\title{
Efficiency of Copper and Selenium during Estrus Synchronization on Estrus Behaviour, Estradiol and Progesterone Concentration in Salem Black Goats
}

J. Nikhil Kumar Tej, P. Johnson, Kalpana Kaushik, Kavya Krishna, S.K. Tripathi, PSP. Gupta, S. Nandi, S. Mondal

10.18805/IJAR.B-4515

\begin{abstract}
Background: Copper and selenium were proven modulaters of reproductive function in ruminants under dietary supplementation. Their effects under pareneral administraton during estrus synchronization are not clearly defined. On this background the present was aimed to evaluate the effect of copper and selenium on estrus associated responses in goats.

Methods: Thirty adult female Salem black goats were selected. On day ten of the estrus cycle, $250 \mu \mathrm{g}$ of cloprostenol injection was given intramuscularly to all the animals and assigned to five groups. GI: control, GII: $4 \mu \mathrm{g}$ of Buserelin, GIII: $20 \mathrm{mg}$ cupric chloride, GIV: $10 \mathrm{mg}$ sodium selenite and GV: copper plus selenium injections were administrated. Whole blood was collected for seven days for hormone assay. Estrus was detected using aproned bucks.

Result: There was no significant $(p>0.05)$ difference in estrus response, onset and duration of estrus between groups. The progesterone concentration decreased significantly $(p<0.05)$ from day 0 (before $\left.\mathrm{PGF}_{2} \alpha\right)$ to day $1\left(\right.$ after $\left.\mathrm{PGF}_{2} \alpha\right)$ in all groups. There was a significant $(p<0.05)$ increase in estradiol and progesterone concentration in the $\mathrm{GnRH}$ group compared to other groups. Parenteral administration of copper and selenium did not significantly improve estrus behavior, estradiol and progesterone concentration in Salem black goats. $\mathrm{GnRH}$ was once again proved to be effective in the improvement of estrus associated responses in goats.
\end{abstract}

Key words: Copper, Estrus, Goats, GnRH, Hormones, Selenium.

\section{INTRODUCTION}

The goat is considered as "poor man's cow" and provides livelihood for billions of low and medium input farmers (Gupta et al., 2019). As India is an agricultural based country, goats are predominantly distributed in India with a population of 148.88 million which constitutes to $27.80 \%$ of the total livestock population (Basic Animal Husbandry Statistics, 2019). The increased demand for goat production is attributed to their regular supply of milk, meat and cashmere. Although, estrus synchronization in goats with progesterone (Pietroski et al., 2013, Hashemi and Safdarian, 2018), estradiol benzoate (Souza-Fabjan et al., 2017), double $\mathrm{PGF}_{2} \alpha$ injections and Ovsynch protocols (Riaz et al., 2012) have been adopted to improve goat population, the estrus response was not always $100 \%$ and the conception rates were below 70\% (Menchaca et al., 2007; Riaz et al., 2012). There is further necessary to tighten the existing synchronization protocols with novel substances that could modulate ovarian function. This research gap is of a greater challenge to the scientific community in the increasing population scenario to enhance the livestock production.

Trace minerals such as copper (Garcia-Diaz et al., 2012; Roychoudhury et al., 2014; Soni et al., 2018) and selenium (Basini and Tamanani et al., 2000; Gabryszuk et al., 2002; Koyuncu and Yerlikaya 2007; Yao et al., 2018) were largely found to regulate ovarian granulosa cell estradiol synthesis and estrus behaviour in ruminants. Copper supplementation in vivo significantly increased
Laboratory of Animal Biotechnology, ICAR-National Institute of Animal Nutrition and Physiology, Bengaluru-560 030, Karnataka, India.

Corresponding Author: J. Nikhil Kumar Tej, Division of Animal Physiology, ICAR-National Dairy Research Institute, Karnal132 001, Haryana, India. Email: drnikhilkumartej@gmail.com

How to cite this article: Tej, J.N.K., Johnson, P., Kaushik, K., Krishna, K., Tripathi, S.K., Gupta, PSP., Nandi, S. and Mondal, S. (2022). Efficiency of Copper and Selenium during Estrus Synchronization on Estrus Behaviour, Estradiol and Progesterone Concentration in Salem Black Goats. Indian Journal of Animal Research. DOI: 10.18805/IJAR.B-4515.

Submitted: 08-05-2021 Accepted: 04-12-2021

Online: $25-01-2022$

estradiol, progesterone, $\mathrm{FSH}$ and $\mathrm{LH}$ concentration in Simmental heifers (Wang et al., 2008). Similarly, selenium supplementation in vivo significantly increased follicular growth (Vázquez-Hernández et al., 2017), estrus response (Gabryszuk et al., 2002; Koyuncu and Yerlikaya 2007; Wani et al., 2016) and conception rate (Ganie et al., 2014; Musa et al., 2018) in ruminants. The existing evidences are based on prolonged dietary supplementation and/or multiple parenteral administrations of copper and selenium, while studies are meager on single parenteral administration of copper and selenium in combination with $\mathrm{PGF}_{2} \alpha$ during estrus synchronization protocols. In view of these considerations an attempt has been made to evaluate the effect of parenteral administration of copper and selenium 
Efficiency of Copper and Selenium during Estrus Synchronization on Estrus Behaviour, Estradiol and Progesterone...

in comparision to $\mathrm{GnRH}$ on estrus behaviour and changes in estradiol and progesterone hormone concentration in Salem black goats.

\section{MATERIALS AND METHODS} Animal management

The present study was conducted in the year 2017-2018 in an experimental livestock unit, ICAR-National Institue of Animal Nutrition and Physiology (NIANP), Adugodi, Bengaluru, Karnataka, India. Thirty adult female Salem black goats of twelve to eighteen months of age were selected. The animals were housed in a well-ventilated shed and maintained under proper hygienic conditions. The animals were fed as per ICAR feeding standards (Ranjhan, 1998).

\section{Experimental design}

Prior to the start of the experiment, all the animals were injected with cloprostenol $250 \mu \mathrm{g} / \mathrm{animal}$ (Pregova, Virbac) to lyse the corpus luteum present if any. Ten days (day 0 of the experiment) after the first injection, the second injection of cloprostenol was injected and the animals were alloted to the following groups. Group I $(\mathrm{GI}, \mathrm{n}=6)$ served as the control, Group II (GII, n=6) animals were given intramuscular injection of $4 \mu \mathrm{g}$ of Buserelin, GnRH analog (Pregulate, Virbac). Group III (GIII, n=6) animals were given intramuscular injection of cupric chloride (Himedia) @ 20 mg per animal. Animals in Group IV (GIV, n=6) were given intramuscular injection of sodium selenite (Sigma Aldrich) @ $10 \mathrm{mg}$ per animal. Groups $\vee(G V, n=6)$ animals were given intramuscular injections of cupric chloride @ 20 mg plus sodium selenite @ $10 \mathrm{mg}$ per animal. The experiment was replicated thrice with a gap of 60 days and the same grouping was followed for each experiment.

\section{Estrus detection}

Estrus was determined initially by signs such as frequent tail wagging, bleating, swollen vulva and vulval mucous discharge. Further confirmation was made by exposing the does to apronised bucks. The female does which stand still on being mounted were considered to be in estrus. Estrus percent was calculated by total number of animals responded in a group divided by total animals of animals in a group. Since the experiment was replicated thrice the percent estrus response of three experiments were used for statistical analysis. The onset and duration of estrus was also recorded.

\section{Blood collection and estimation of plasma estradiol and progesterone concentration}

Whole blood was collected from day 0 to day 7 from all the animals. The plasma was separated by centrifugation at 3500 rpm for $15 \mathrm{~min}$ at room temperature and stored at $-20^{\circ} \mathrm{C}$ for estimation of estradiol and progesterone hormone concentration. Plasma estradiol (Tsang et al., 1980) and progesterone (Radwanska, 1978) concentration was determined by enzyme linked immunosorbent assay (ELISA) using a microplate reader (Thermo Scientific) by ELISA kits (Cal biotech kits).

\section{Statistical analysis}

The data obtained on various parameters were statistically analyzed using Graphpad PRISM software 6.0. The differences between means of different groups were analyzed by one way ANOVA and multiple comparisons were performed by Tukey'stest. The percentage values of estrus response were converted to arcsine values before statistical analysis and significance was determined at $P<0.05$.

\section{RESULTS AND DISCUSSION}

Trace minerals hold critical roles in maximizing reproductive efficiencies in ruminants. The trace elements likely to be of most practical significance are copper, selenium and zinc (Pal, 2015). It has been established that copper has a stimulatory effect on the release of $\mathrm{GnRH}$ and $\mathrm{FSH}$ (Rouchoudhary et al., 2016) which triggers the synthesis and release of estradiol. Furthermore, copper inpart may promote ovarian granulosa cell estradiol synthesis via mRNA expression of Cytochrome P450 Family 19 subfamily $A$ member 1(CYP19A1) which encodes the enzyme aromatase that converts androgens to estradiol in the ovarian granulosa cells (Soni et al., 2018; Tej et al., 2021). Selenium was found to stimulate ovarian granulosa cell estradiol synthesis via increase in the number of follicles (Vázquez-Hernández et al., 2017) granulosa cell proliferation (Basini and Tamanini, 2000), increased activity of antioxidant enzymes, reduce lipid peroxidation (Said et al., 2012) and upregulation of genes involved in estradiol synthesis signalling pathways (Yao et al., 2018). These evidences suggest that, trace minerals such as copper and selenium could be possibly used to improve estrus response in synchronization protocols.

\section{Effect of copper and selenium on estradiol concentration}

Within-group between days comparison (Fig 1) revealed no significant $(p>0.05)$ increase in estradiol concentration from day 0 to day 7 in all the groups. Between group comparison (Fig 2) revealed significantly higher $(p<0.05)$ estradiol concentration in $\mathrm{GnRH}$ group compared to other groups, while the estradiol concentration did not differ significantly $(p>0.05)$ between control, copper, selenium, copper plus selenium groups. The significant $(p<0.05)$ increase in estradiol concentration in $\mathrm{GnRH}$ group compared to other groups could be attributed to $\mathrm{GnRH}$ injection which stimulates $\mathrm{FSH}$ secretion from the anterior pituitary and subsequent follicular growth and estradiol synthesis from granulosa cells (Marques et al., 2018). No significant $(p>0.05)$ effect of copper and selenium on estradiol concentration was observed in the present study. Contradictory to the present findings, dietary supplementation of copper sulphate (Wang et al., 2008) significantly increased estradiol concentration in ruminants. Moreover, oral supplementation of sodium selenite in ewe (Sen et al., 2011) and selenium rich yeast in Taihang black goats (Shi et al., 2018) significantly increased estradiol concentration. The significant increase in estradiol concentration with copper and selenium in other studies could be due to 


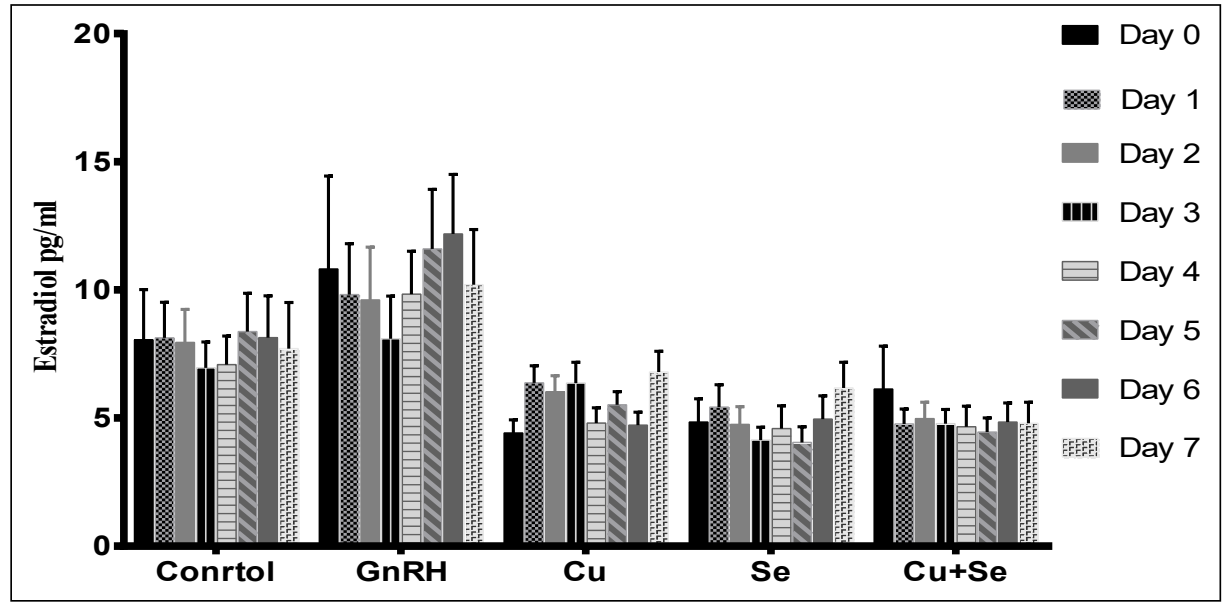

Fig 1: Changes in estradiol concentration $(\mathrm{pg} / \mathrm{ml})$ from day 0 (before $\mathrm{PGF}_{2} \alpha$ ) to day 7 in different groups of Salem black goats. The graph represents within group between days comparison of estradiol concentration from day 0 to day $7, p<0.05(n=18)$.

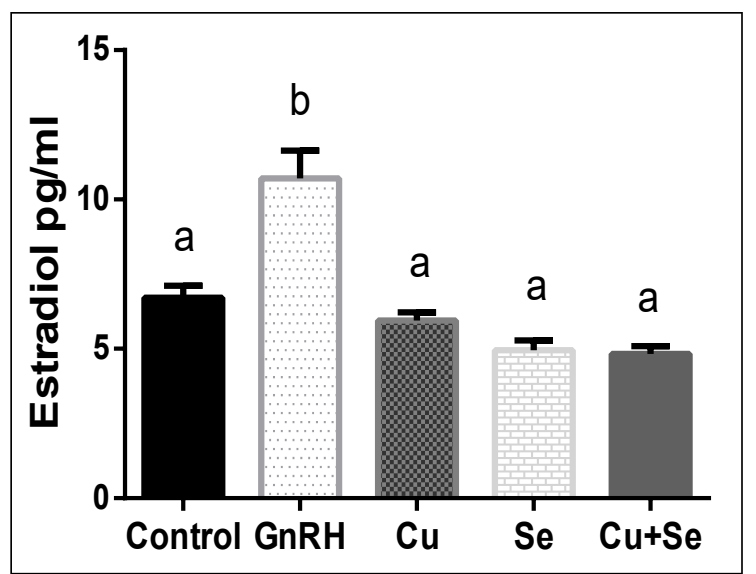

Fig 2: Overall estradiol concentration $(\mathrm{pg} / \mathrm{ml})$ in different groups of Salem black groups. The graph represents the average of estradiol concentration from day 0 to day 7 , bars bearing different superscript $(a, b)$ differs significantly, $p<0.05 \quad(n=18)$.

prolonged dietary supplementation. The estradiol concentration observed in the present study was in agreement with other reports where a similar estradiol concentration of $7.7 \pm 1.7 \mathrm{pg} / \mathrm{ml}$ in Dwarf goats (Khanum et al., 2008) and $5.19 \pm 0.71 \mathrm{pg} / \mathrm{ml}$ in Huanghuai Goats (Pang et al., 2009) was observed.

\section{Effect of copper and selenium on progesterone concentration}

Within group between days comparison (Fig 3) revealed that the progesterone concentration was significantly higher $(p<0.05)$ on day 0 (before $\mathrm{PGF}_{2} \alpha$ injection) in all the groups and the concentration decreased significantly $(p<0.05)$ on day 1 and continued to maintain at significantly $(p<0.05)$ lower levels till day 5 in all the groups. Between groups comparison (Fig 4) revealed significantly $(p<0.05)$ higher progesterone concentration in $\mathrm{GnRH}$ group compared to other groups, while the progesterone concentration did not differ significantly $(p>0.05)$ between control, copper, selenium, copper plus selenium groups. A significant $(p<0.05)$ decline in progesterone concentration from day 0 to day 1 could be due to $\mathrm{PGF}_{2} \alpha$ injection which selectively lyses the developing corpus luteum (CL) (Omontese et al., 2016) and subsequent decrease in progesterone concentration. A significant $(p<0.05)$ increase in progesterone concentration in the $\mathrm{GnRH}$ group compared to other groups could be attributed to $\mathrm{GnRH}$ injection which would have stimulated $\mathrm{LH}$ secretion and subsequent progesterone synthesis from luteal cells (Marques et al., 2018). The study revealed no significant $(p>0.05)$ effect of copper and selenium on progesterone concentration in Salem black goats. Contradictory to our findings dietary supplementation of copper sulphate (Wang et al., 2008) significantly increased progesterone concentration in ruminants. Moreover, oral supplementation of sodium selenite (Kamada et al., 2014), selenium (Cerny et al., 2016) selenium enriched yeast (Shi et al., 2018) significantly increased progesterone concentration in ruminants which may be due to prolonged dietary supplementation of copper and selenium. The progesterone concentration observed in the present study was in agreement with other reports where a progesterone concentration of 0.1 to $5.4 \mathrm{ng} / \mathrm{ml}$ in Dwarf goats (Khanum et al., 2006), $0.1 \pm 0.03$ to $7.7 \pm 0.6 \mathrm{ng} / \mathrm{ml}$ in Dwarf goats (Khanum et al., 2008) and $0.51 \pm 0.10$ to $10.72 \pm 0.71 \mathrm{ng} / \mathrm{ml}$ in Markhoz Goat (Farshad et al., 2008) was observed respectively.

Effect of copper and selenium on estrus response, onset and duration of estrus

The mean \pm SEM values of onset, duration and estrus response were presented in Table 1. There was no significant $(p>0.05)$ difference in onset, duration and estrus response between groups. In the estrus cycle of the goat, at the end of diestrus phase $\mathrm{PGF}_{2} \alpha$ secreted from the uterine 


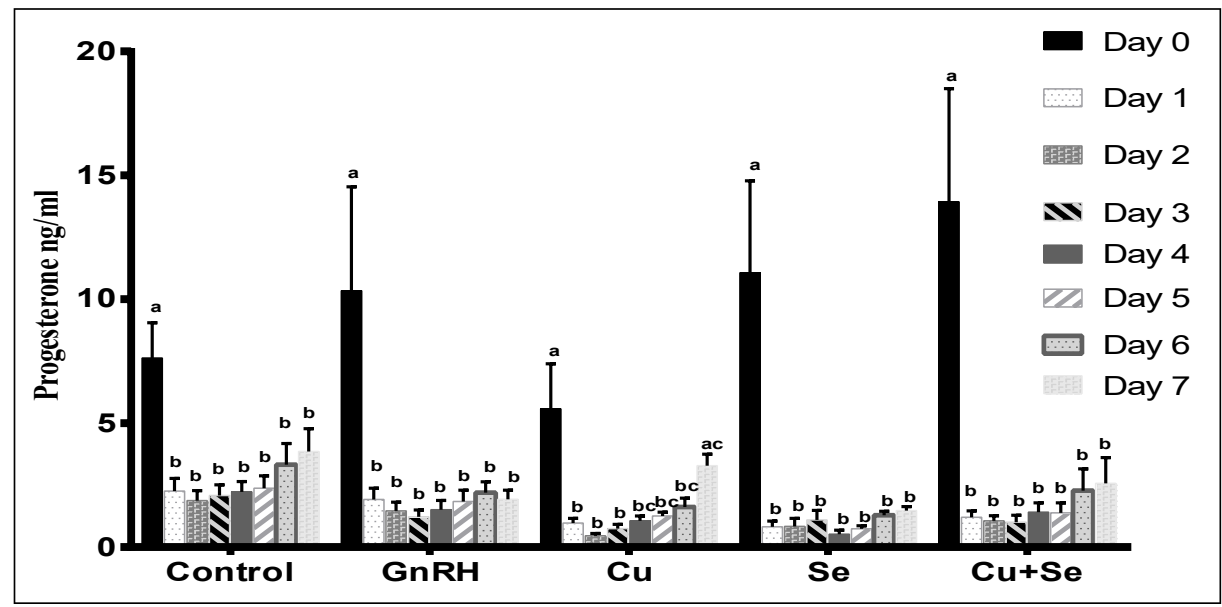

Fig 3: Changes in progesterone concentration $(\mathrm{ng} / \mathrm{ml}$ ) from day 0 (before PGF2 $\alpha$ ) to day 7 in different groups of Salem black goats. The graph represents within group between days comparison of progesterone concentration from day 0 to day 7 . Bars bearing different superscript $(a, b)$ with in a group differs significantly, $p<0.05,(n=18)$.

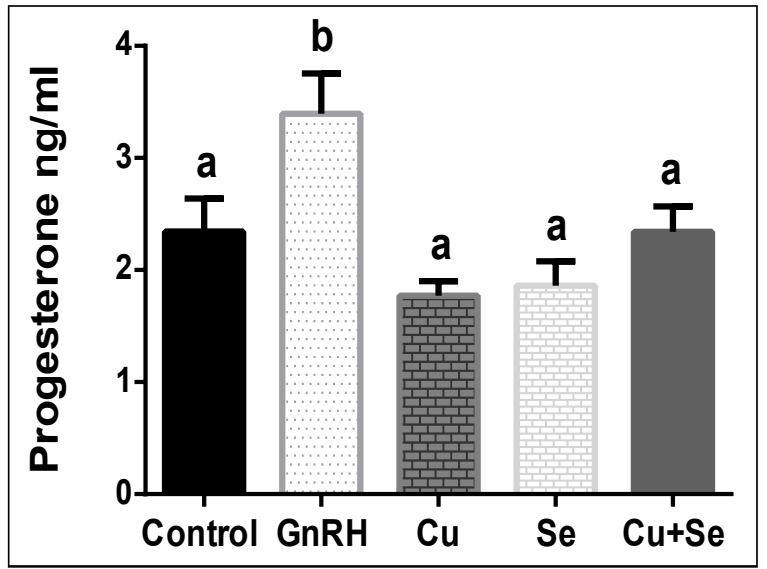

Fig 4: Overall progesterone concentration $(\mathrm{pg} / \mathrm{ml})$ in different groups of Salem black goats. The graph represents the average of progesterone concentration from day 0 to day 7 , bars bearing different superscript $(a, b)$ differs significantly, $p<0.05(n=18)$.

endoemetrium lyse the $\mathrm{CL}$, lowering the progesterone concentration. This reduced progesterone triggers the secretion of $\mathrm{GnRH}$ from hypothalamus and subsequent secretion of $\mathrm{FSH}$ from anterior pituitary. Under the influence of tonic FSH secretions the existing dominant follicle of the follicular wave continuous to secrete estradiol which induce estrus behaviour and when the estradiol concentration reaches peack it triggers ovulation (Fatet et al., 2011). In the current study, low estrus response was noticed in control groups ( $\mathrm{PGF}_{2} \alpha$ alone). Similar to our findings, a low estrus response of $4.3-15.8 \%$ in Red Sokoto goats (Tauheed et al., 2010), 30\% in Persian downy does (Hashemi and Safdarian, 2018) and 0\% in Salem black goats (Gupta et al., 2019) was observed in goats synchronized with double $\mathrm{PGF}_{2}$ a protocol. Relatively, a high estrus response of $50 \%$ was observed in $\mathrm{GnRH}$ group. Similar estrus response was observed in our previous study on Salem black goats where
GnRH based Ovisynch Protocol was used (Gupta et al., 2019). This effect may be attributed to $\mathrm{GnRH}$ injection which would have directly trigerred hypothalamic-pituitary-ovarian axis. Furthermore, low estrus response was observed in copper and selenium groups. No similar studies were conducted so far to compare our results but selenium when injected with sponge impregnated with progesterone it resulted in 90\% (Qureshi et al., 2010), 88\% (Wani et al., 2016) and $100 \%$ (Mujawar et al., 2019) estrus response in buffaloes.

The onset of estrus observed in the present study fall in line with other studies where double $\mathrm{PGF}_{2} \alpha$ injection resulted in onset of estrus of 45-45.5 $\mathrm{h}$ in Black bengal does (Khandoker et al., 2009) and $47.7 \pm 10.1 \mathrm{~h}$ in Alpine, Saanen and Toggenburg cross (Esteves et al., 2013). The finding of the present study was in agreement with other reports where goats synchronized with $\mathrm{PGF}_{2} \alpha$ showed a duration of estrus of 25-51h in Black bengal does (Khandoker et al., 2009) and $26.8 \pm 15.0 \mathrm{~h}$ in Alpine, Saanen and Toggenburg cross (Esteves et al., 2013) respectively. The onset and duration of estrus observed in the present study falls within the range as that of other breeds of goats and this information is important for the determination of the time of mating and or insemination to maximize reproductive efficiency in goats.

In the present study, copper and selenium did not significantly affect estradiol, progesterone, estrus response, onset and duration of estrus, while GnRH injection significantly improved estrus associated responses compared to other groups. Whereas, from other studies it was evident that selenium and progesterone combination resulted in high estrus response in buffaloes (Qureshi et al., 2010; Wani et al., 2016; Mujawar et al., 2019). The findings are suggestive of use of copper and selenium in combination with $\mathrm{GnRH} /$ progesterone devices to evaluate the effect on estrus associated responses. Moreover single injection of minerals just before estrus might have not improved estradiol synthesis significantly which may be due to the limitations imposed by other competing factor (Landau, 
Efficiency of Copper and Selenium during Estrus Synchronization on Estrus Behaviour, Estradiol and Progesterone...

Table 1: Mean \pm SE values of onset, duration and estrus response in Salem black goats $(n=18)$.

\begin{tabular}{lccccc}
\hline Parameters & Control & GnRH & $\mathrm{Cu}$ & $\mathrm{Se}$ & $\mathrm{Cu}+\mathrm{Se}$ \\
\hline Onset $(\mathrm{h})$ & $51.5 \pm 36.5$ & $66.81 \pm 15.69$ & $30.13 \pm 6.07$ & $40.17 \pm 13.86$ & $43.75 \pm 4.25$ \\
Duration $(\mathrm{h})$ & $39.75 \pm 8.75$ & $37.97 \pm 5.15$ & $39.81 \pm 4.80$ & $24.00 \pm 4.36$ & $47.75 \pm 8.25$ \\
Estrus response (\%) & $20.60 \pm 10.60$ & $49.22 \pm 7.30$ & $23.49 \pm 11.75$ & $23.01 \pm 13$ & $11.75 \pm 11.75$ \\
\hline
\end{tabular}

2000) as copper and selenium are involved in diverse functions, the given dose would have utilized for general body functions. While the significant effect of copper and selenium in other studies could be due to prolonged dietary supplementation and or multiple injections.

\section{CONCLUSION}

Although copper and selenium were proved to be estrogenic in ruminants, in the current study no significant effect was noticed. It was concluded that single parenteral injection of copper and selenium along with $\mathrm{PGF}_{2} \alpha$ did not improve estrus behavior, estradiol and progesterone concentration in Salem black goats. Whereas GnRH was proved to be effective in improving the reproductive efficiency in goats. Therefore, the current study strongly hints a necessity for the use of combintion of $\mathrm{GnRH} /$ progesterone along with trace minerals. However, in the present study no such combinations were used. Further studies are focussed on use of copper and selenium in combination with $\mathrm{GnRH}$ / progesterone devices.

\section{ACKNOWLEDGEMENT}

The authors are greatly thankful to the Director, National Institute of Animal Nutrition and Pysiology (NIANP), for provision of facilities at the laboratories and livestock farm.

\section{Compliance with ethical standards}

The animal studies have been approved by the appropriate ethics committee, F.No25.08.2016- CPCSEA, (part-I), dt 20.05.2016, Govt. of India and have therefore been performed in accordance with the ethical standards laid down in the 1964 Declaration of Helsinki and its later amendments.

\section{Conflict of interest}

The authors declare that they have no competing interests.

\section{REFERENCES}

Basic Animal Husbandry Statistics. (2019). Government of India, Ministry of Fisheries, Animal Husbandry and Dairying, Department of Animal Husbandry and Dairying, Krishi Bhavan. New Delhi.

Basini, G. and Tamanini, C. (2000). Selenium stimulates estradiol production in bovine granulosa cells: Possible involvement of nitric oxide. Domestic Animal Endocrinology. 18(1): 1-17.

Cerny, K.L., Anderson, L., Burris, W.R., Rhoads, M., Matthews, J.C., Bridges, P.J. (2016). Form of supplemental selenium fed to cycling cows affects systemic concentrations of progesterone but not those of estradiol. Theriogenology. 85(5): 800-806.
Esteves, L.V., Brandão, F.Z., Cruz, R.C., Souza, J.M.G., Oba, E., Facó, O., Fonseca, J.F. (2013). Reproductive parameters of dairy goats submitted to estrus synchronization with prostaglandin $\mathrm{F} 2 \alpha$ associated or not to $\mathrm{hCG}$ at estrous onset. Arquivo Brasileiro de Medicina Veterinária e Zootecnia. 65(6): 1585-1592.

Farshad, A., Akhondzadeh, M.J., Zamiri, M.J., Sadeghi, G.H. (2008). The estrous cycle of the Markhoz goat in Iran. AsianAustralasian Journal of Animal Sciences. 21(10): 14111415.

Fatet, A., Pellicer-Rubio, M.T., Leboeuf, B. (2011). Reproductive cycle of goats. Animal Reproduction Science. 124(3-4): 211-219.

Gabryszuk, M. and Klewiec, J. (2002). Effect of injecting 2-and 3year-old ewes with selenium and selenium-vitamin $E$ on reproduction and rearing of lambs. Small Ruminant Research. 43(2): 127-132.

Ganie, A.A., Baghel, R.P.S., Mudgal, V., Aarif, O., Sheikh, G.G. (2014). Effect of selenium supplementation on reproductive performance and hormonal profile in buffalo heifers. Indian Journal of Animal Research. 48: 27-30.

García-Díaz, J.R., Joseph-Ajakaiye, J., Cuesta-Mazorra, M., QuiñonesRamos, R., Munyori-Nderitu, H., Figueredo-Ross, J.M., Mollineda-Trujillo, Á. (2012). Effects of parenteral supplementation of $\mathrm{Cu}$ in female cattle with different levels of cupremia. Archives Animal Breeding. 55(2): 113-122.

Gupta, P.P., Nikhil Kumar Tej, J., Johnson, P., Nandi, S., Mondal, S., Kaushik, K., Krishna, K. (2019). Efficiency of different synchronization protocols on oestrous response and rhythmic changes in $17 \beta$-oestradiol and progesterone hormone concentration in Salem Black goats. Biological Rhythm Research. 52(1): 11-21.

Hashemi, M. and Safdarian, M. (2018). Efficiency of different methods of estrus synchronization followed by fixed time artificial insemination in Persian downy does. Animal Reproduction. 14(2): 413-417.

Kamada, H., Nonaka, I., Takenouchi, N., Amari, M. (2014). Effects of selenium supplementation on plasma progesterone concentrations in pregnant heifers. Animal Science Journal. 85(3): 241-246.

Khandoker, M.A.M.Y., Sultana, A., Akter, Q.S., Tareq, K.M.A., Mia, M.M., Husain, S.S., Notter, D.R. (2009). Synchronization of estrus in black Bengal does. Bangladesh Journal of Animal Science. 38(1-2): 7-14.

Khanum, S.A., Hussain, M., Kausar, R. (2006). Manipulation of estrous cycle in Dwarf goat (Capra hircus) using estrumate under different management conditions. Animal Reproduction Science. 92(1-2): 97-106.

Khanum, S.A., Hussain, M., Kausar, R. (2008). Progesterone and estradiol profiles during estrous cycle and gestation in Dwarf goats (Capra hircus). Pakistan Veterinary Journal. 28(1): 1. 
Koyuncu, M.E.H.M.E.T. and Yerlikaya, H. (2007). Short communication effect of selenium-vitamin $E$ injections of ewes on reproduction and growth of their lambs. South African Journal of Animal Science. 37(4): 233-236.

Landau, S., Braw-Tal, R., Kaim, M., Bor, A., Bruckental, I. (2000). Preovulatory follicular status and diet affect the insulin and glucose content of follicles in high-yielding dairy cows. Animal Reproduction Science. 64(3-4): 181-197.

Marques, P., Skorupskaite, K., George, J.T. anderson, R.A. (2018). Physiology of $\mathrm{GnRH}$ and gonadotropin secretion. Endotext [Internet].

Menchaca, A. and Rubianes, E. (2007). Pregnancy rate obtained with short term protocol for timed artificial insemination in goats. Reproduction in Domestic Animals. 42(6): 590-593.

Mujawar, A.S., Razzaque, W.A.A., Ramteke, S.S., Patil, A.D., Ali, S.S., Bhikane, A.U. (2019). Estrus induction and fertility response in postpartum anoestrus Marathwadi buffaloes using hormonal protocol along with vitamin $\mathrm{E}$ and Selenium. International Journal of Livestock Research. 9(3): 289-96.

Musa, S.I., Bitto, I.I., Ayoade, J.A., Oyedipe, O.E. (2018). Effects of vitamin $E$ and selenium on fertility and lamb performance of yankasa sheep. Open Journal of Veterinary Medicine. 8(09): 167.

Omontese, B.O., Rekwot, P.I., Ate, I.U., Ayo, J.O., Kawu, M.U., Rwuaan, J.S., Nwannenna, A.I., Mustapha, R.A., Bello, A.A. (2016). An update on oestrus synchronisation of goats in Nigeria. Asian Pacific Journal of Reproduction. 5(2): 96-101.

Pal, A. (2015). Role of copper and selenium in reproductive biology: A brief update. Biochem Pharmacology. 4(4): 5.

Pang, X.S., Wang, Z.Y., Zhu, T.G., Yin, D.Z., Zhang, Y.L., Meng, L., Wang, F. (2009). Concentrations of progesterone and estradiol in peripheral plasma during the estrous cycle and after ovariectomy in Huanghuai goats of high or poor prolificacy. Asian-Australasian Journal of Animal Sciences. 23(2): 188-196.

Pietroski, A.C.C.A., Brandão, F.Z., Souza, J.M.G.D., Fonseca, J.F.D. (2013). Short, medium or long-term hormonal treatments for induction of synchronized estrus and ovulation in Saanen goats during the nonbreeding season. Revista Brasileira de Zootecnia. 42(3): 168-173.

Qureshi, Z.I., Siddiq, M., Lodhi, L.A., Muhammad, G., Jamil, H. (2010). Effect of vitamin E-selenium administration during late gestation on productive and reproductive performance in dairy buffaloes and on growth performance of their calves. Pakistan Veterinary Journal. 30(2): 83-6.

Radwanska, E., Frankenberg, J., Allen, E.I. (1978). Plasma progesterone levels in normal and abnormal early human pregnancy. 30(4): 398-402.

Ranjhan, S.K. (1998). Nutrient Requirements of Livestock and Poultry. $9^{\text {th }}$ Edn. New Delhi, Indian Council of Agriculture Research. Pp. 7.

Riaz, H., Sattar, A., Arshad, M.A., Ahmad, N. (2012). Effect of synchronization protocols and $\mathrm{GnRH}$ treatment on the reproductive performance in goats. Small Ruminant Research. 104(1-3): 151-155.

Roychoudhury, S., Bulla, J., Sirotkin, A.V., Kolesarova, A. (2014). In vitro changes in porcine ovarian granulosa cells induced by copper. Journal of Environmental Science and Health, Part A. 49(6): 625-633.
Roychoudhury, S., Nath, S., Massanyi, P., Stawarz, R., Kacaniova, M., Kolesarova, A. (2016). Copper-induced changes in reproductive functions: In vivo and in vitro effects. Physiological Research. 65(1).

Said, R.S., Nada, A.S., El-Demerdash, E. (2012). Sodium selenite improves folliculogenesis in radiation-induced ovarian failure: A mechanistic approach. PloS One. 7(12): 50928.

Sen, W., Fucai, C., Yanyan, W., Zhanqin, Z. (2011). Effects of selenium supplement on the serum hormone concentration and super ovulation effect of Suffolk sheep. Chinese Agricultural Science Bulletin. 23: 9-23.

Shi, L., Ren, Y., Zhang, C., Yue, W., Lei, F. (2018). Effects of organic selenium (Se-enriched yeast) supplementation in gestation diet on antioxidant status, hormone profile and haematobiochemical parameters in Taihang Black Goats. Animal Feed Science and Technology. 238: 57-65.

Soni, R.K., Gupta, P.S.P., Nandi, S., Mondal, S., Ippala, J.R., Mor, A., Mishra, A., Tripathi, S.K. (2018). Effect of in vitro copper supplementation on granulosa cell estradiol synthesis and associated genes. Indian Journal of Animal Research. 52(5).

Souza-Fabjan, J.M.G., da Rosa, R.M., Balaro, M.F.A., Pinto, P.H.N., Dos Santos, G.B., Arashiro, E.K.N., da Fonseca, J.F., Ungerfeld, R., Brandão, F.Z. (2017). Effect of different hormonal combinations on follicular wave emergence and superovulatory response in sheep. Theriogenology. 103: 24-29.

Tauheed, M. (2010). The effect of dose and parity on oestrus response and fertility following single treatment with prostaglandin F2 $\alpha$ in anoestral Red Sokoto goats during the mid-rainy season. DVM project, Faulty of veterinary medicine, Zaria Ahmadu Bello University.

Tej, J.N., Johnson, P., Krishna, K., Kaushik, K., Gupta, P.S., Nandi, S., Mondal. S. (2021). Copper and Selenium stimulates CYP19A1 expression in caprine ovarian granulosa cells: Possible involvement of AKT and WNT signalling pathways. Molecular Biology Reports. 21: 1-3.

Tsang, B.K., Armstrong, D.T., Whitfield, J.F. (1980). Steroid biosynthesis by isolated human ovarian follicular cells in vitro. The Journal of Clinical Endocrinology and Metabolism. 51(6): 1407-1411.

Vázquez-Hernández, S.D., Miranda-Jiménez, L., Segura-León, O., Quero-Carrillo, A.R. (2017). Goats' follicle and corpora lutea development as a response to selenium supply. Agroproductividad. 10(2): 15-18.

Wang, C., Huang, Y., Dong, K., Liu, Q., Huo, W. (2008). Effects of copper sulfate on reproductive hormone level during estrous cycle in simmental heifers. Acta Agriculturae Nucleatae Sinica. 22(2): 228-232.

Wani, M.A., Razzaque, W.A., Sharma, U. (2016). Effect of vitamin$E$ and selenium supplementation on oxidative stress parameters in postpartum anestrus Buffaloes. Journal of Animal Research. 6(4): 629.

Yao, X., Ei-Samahy, M.A., Fan, L., Zheng, L., Jin, Y., Zhang, G., Liu, Z., Wang, F. (2018). In vitro influence of selenium on the proliferation of and steroidogenesis in goat luteinized granulosa cells. Theriogenology. 114: 70-80. 